\title{
Determinantes do empreendedorismo no Rio Grande do Sul: uma análise espacial
}

\author{
Ricardo Höher \\ Universidade Federal de Santa Maria (UFSM) \\ Mário Jaime Gomes de Lima \\ Centro Universitário La Salle Canoas (Unilasalle) \\ Adelar Focheratto \\ Pontifícia Universidade Católica do Rio Grande do Sul (PUCRS)
}

Recebido: 18/12/2016 Versão revisada (entregue): 06/03/2018 Aprovado: 13/03/2018

\begin{abstract}
Resumo
O objetivo do presente trabalho foi testar a hipótese de que regiões, no Estado do Rio Grande do Sul, com elevado nível de urbanização, educação formal e renda per capita, tendem a ter um maior grau de empreendedorismo, buscando-se identificar o empreendedorismo espacialmente e diferenciá-lo em "de oportunidade" ou "de necessidade". Para isto, foi realizada, como metodologia proposta para este trabalho, uma Análise Exploratória de Dados Espaciais (AEDE), utilizando-se o Índice de Moran e indicadores de associação espacial local. A partir da aplicação da metodologia proposta e dos resultados encontrados, teve-se confirmada a hipótese. Assim, pode-se concluir, primeiramente, que o empreendedor local tende a criar novos negócios em função de oportunidades e, depois, que a Serra Gaúcha se apresenta como a região com maior propensão para o empreendedorismo no Estado do Rio Grande do Sul.
\end{abstract}

Palavras-chave | Análise espacial; desenvolvimento regional; economia regional; empreendedorismo; Rio Grande do Sul.

Código JEL | L26; M13; R12.

\section{DETERMINANTS OF ENTREPRENEURSHIP IN RIO GRANDE DO SUL: A SPATIAL ANALYSIS}

\begin{abstract}
The objective of this study was to test the hypothesis that regions, in Rio Grande do Sul, with high level of urbanization, education and per capita income, tend to have a higher degree of entrepreneurial. In which sought to identify spatially and differentiate entrepreneurship in opportunities or needs. For this, was carried out, an Exploratory Spatial Data Analysis - ESDA, the Moran index and the use of local spatial association indicators. From the application of the proposed methodology, the results confirm the hypothesis tested and it conclued: The local
\end{abstract}


entrepreneur creates new business opportunities in function, in which highlights, the region of the state have seen a strong propensity for entrepreneurship.

Keywords | Entrepreneurship; regional development; regional economics; Rio Grande do Sul; spatial analysis.

JEL-Code | L26; M13; R12.

\section{DETERMINANTES DEL ESPÍRITU EMPRESARIAL EN RIO GRANDE DO SUL: UN ANÁLISIS ESPACIAL}

\section{Resumen}

El objetivo de este estudio fue probar la hipótesis de que las regiones, en el estado de Rio Grande do Sul, con un alto nivel de urbanización, educación e ingreso per cápita, tienden a tener un mayor grado de iniciativa empresarial, buscándose identificar el espíritu empresarial espacialmente y diferenciarlo entre "de oportunidad" o "de necesidad". Para ello, se realizó, como metodología propuesta para este trabajo, un Análisis Exploratorio de Datos Espaciales (AEDE), utilizando el índice de Moran e indicadores de asociación espacial locales. A partir de la aplicación de la metodología propuesta y de los resultados encontrados, se confirma la hipótesis. Así, se puede concluir, primeramente, que el empresario local tiende a crear nuevos negocios en función de oportunidades y, después, que la Serra Gaucha se destaca como la región con mayor propensión a la iniciativa empresarial en el Estado de Rio Grande do Sul.

Palabras-clave | Análisis espacial; desarrollo regional; economía regional; espíritu empresarial; Rio Grande do Sul.

Código JEL | L26; M13; R12.

\section{Introdução}

O termo empreendedorismo é compreendido como atividade ou ação que requer a criação de um novo produto ou serviço ou até mesmo a concepção de um novo negócio. Trata-se do rompimento do usual ou existente, em busca do novo, provocado pela criação ou utilização de novas combinações de recursos (SCHUMPETER, 1934; PAIVA et al, 2018). O empreendedorismo desempenha relevante papel para a inovação e a competitividade, bem como para o desenvolvimento econômico, sendo considerado essencial para o crescimento econômico de regiões e países.

O surgimento de novos negócios é condição determinante para o desenvolvimento de economias regionais. A partir do empreendedorismo há o surgimento de inovações e, além disso, são gerados fatores de produção que, por consequência, proporcionam novos postos de trabalho e, desta forma, estimulam o crescimento econômico e social. Portanto, regiões onde a população é composta por grande número de indivíduos capazes, preparados e dispostos a empreender 
são intrinsecamente mais desenvolvidas e apresentam melhores condições econômicas (LONGENECKER et al., 1997).

Para Nijkamp (2009), o empreendedorismo local pode ser fortalecido a partir de parcerias firmadas entre o agente público e o setor privado, podendo assim estabelecer condições para o surgimento de novos negócios, por meio de contribuições produtivas para o trabalho e talentos cognitivos das pessoas, da possibilidade de acesso a recursos financeiros e de investimentos em educação e pesquisa.

De acordo com Souza et al (2011), a abertura de novas firmas está ligada aos potenciais empreendedores de uma determinada região, além de outros aspectos correlatos. Segundo a literatura, vários elementos podem contribuir para estimular o empreendedorismo, tais como urbanização, taxa de imigração, participação da mulher no mercado de trabalho, grau de escolaridade, nível de emprego, entre outros. Desta forma, é importante a identificação de quais são os fatores que fortalecem a cultura empreendedora, em um determinado local, e quais são os que retraem o surgimento de novas empresas.

Portanto, de acordo com o exposto, este estudo objetivou testar a hipótese de que regiões no estado do Rio Grande do Sul, com elevado nível de urbanização, educação e renda per capita, tendem a ter um maior grau de empreendedorismo, sendo estes fatores que fortalecem o surgimento de novos negócios. Para tal foram utilizados instrumentos metodológicos para a elaboração da análise, bem como, para a definição das variáveis independentes mais adequadas na elaboração do modelo explicativo do empreendedorismo gaúcho.

Além desta seção, foram elaboradas outras três, sendo apresentada na seguinte uma revisão teórica para embasamento acerca do tema empreendedorismo no contexto do desenvolvimento regional, englobando questões como inovação e aspectos espaciais. Na terceira seção foi demonstrada a metodologia utilizada para o desenvolvimento deste estudo, a partir da Análise Exploratória de Dados Espaciais (AEDE), do Índice de Moran e a utilização de indicadores de associação espacial local (LISA), bem como a aplicação de um modelo de regressão linear. Por fim, na seção subsequente, foram apresentadas as análises e os resultados obtidos na execução do modelo proposto.

\section{Empreendedorismo e desenvolvimento regional}

\section{A inovação como variável determinante do desenvolvimento regional}

As teorias sobre o desenvolvimento regional constantemente referem-se à localização e aos aspectos de mobilização de recursos, como infraestrutura, novas tecnologias ou outras condições, que promovam as vantagens competitivas das 
regiões. Neste contexto, a competitividade regional e territorial está condicionada à promoção e valorização de externalidades da competitividade empresarial, por meio da intervenção no ambiente externo da competitividade das empresas, através do desenvolvimento de economias de aglomeração, do conhecimento implícito das regiões, e do meio inovador, como um instrumento econômico intangível, nos modelos de crescimento endógeno e externalidades (FIGUEIREDO, 2009).

Tendo a inovação como elemento intangível na composição do desenvolvimento regional, os estudos têm se dirigido para locais e regiões que apresentam eficiência de mercado, além de capacidade de organização. Desta forma, o desenvolvimento regional fundamenta-se na inovação empresarial que pode ser fortalecida pelo comportamento empreendedor local.

O empreendedorismo assume importância central entre os processos que afetam as mudanças econômicas regionais, em que os empresários são os responsáveis pela mudança, podendo acelerar a implementação de novas ideias. Ademais, o empreendedorismo local ou regional ganha importância para o desenvolvimento de uma região, sendo o indicador para a avaliação do crescimento e o desempenho de determinados locais (NIJKAMP, 2009). Dentro deste contexto, o empreendedorismo é um comportamento social eminentemente estudado por diferentes autores e abordagens, com destaque para alguns estudos (Tabela1).

\section{Tabela 1 - Estudos sobre empreendedorismo}

\begin{tabular}{l|l}
\hline \multicolumn{1}{c|}{ AUTOR } & \multicolumn{1}{c}{ FOCO DO ESTUDO } \\
\hline $\begin{array}{l}\text { LUMPKIN; DESS, } \\
1996\end{array}$ & $\begin{array}{l}\text { Compreende empreendedorismo como a busca por } \\
\text { novos mercados. }\end{array}$ \\
\hline $\begin{array}{l}\text { PEREIRA; BARROS, } \\
2008\end{array}$ & $\begin{array}{l}\text { Estudou como as taxas de empreendedorismo entre } \\
\text { regiões afetam o desenvolvimento econômico. }\end{array}$ \\
\hline $\begin{array}{l}\text { THORNTON et al., } \\
2011\end{array}$ & $\begin{array}{l}\text { Incluiu no seu estudo como o processo cultural } \\
\text { interfere no empreendedorismo. }\end{array}$ \\
\hline $\begin{array}{l}\text { MENEZES; } \\
\text { CANEVER, 2016 }\end{array}$ & $\begin{array}{l}\text { Apresentou em seus estudos a relação da taxa de } \\
\text { formação de novas empresas com a estrutura } \\
\text { empresarial local dos municípios gaúchos }\end{array}$ \\
\hline
\end{tabular}

Fonte: Elaborado pelo autor.

Assim, quando inserido em um contexto espacial, o empreendedorismo local ou regional é influenciado por aspectos e variáveis, que atuam como fatores motivadores ou limitadores, como, por exemplo, o capital humano; o capital 
empresarial; o capital financeiro; o capital social; o capital intelectual; e o capital criativo (NIJKAMP, 2009). Essas variáveis apresentam-se mais abundantes em regiões com um espaço socioeconômico integrado, gerado a partir de, pelo menos, uma cidade-núcleo e cidades vizinhas com trânsito pendular de trabalhadores, além de intensos laços econômicos. Desta forma, constituindo um espaço urbanizado, caracterizado por um ambiente com infraestrutura e oferta de serviços de alta especificidade, materializando economias de aglomeração (FRANÇA; FURTADO, 2013).

Com isso, torna-se necessário observar em que contexto espacial o empreendedorismo tem maiores condições de ocorrer, bem como, quais são os outros possíveis condicionantes espaciais, que irão supostamente determinar o seu progresso, para então, consequentemente, o empreendedorismo colaborar para o desenvolvimento regional.

\section{Contexto espacial do empreendedorismo e do desenvolvimento regional}

No Brasil, o processo de urbanização é caracterizado pela aglomeração de pessoas nas capitais ou municípios-polos, o que pode retrair a instalação de indústrias e o desenvolvimento de outras atividades que contribuem para geração de emprego e renda, em regiões formadas, predominantemente, por cidades de pequeno e médio porte, isoladas ou distantes dos grandes centros urbanos. Desta forma, prejuízos às comunidades interioranas podem ocorrer, em razão da falta de oportunidade de trabalho, o que vem a forçar, muitas vezes, o deslocamento da população para outra região ou município.

...a distribuição espacial da população pela via do emprego, com base nos recursos e sua localização, deixando o caminho aberto ao aparecimento de cidades de diferentes tamanhos [...] o desenvolvimento das atividades, influenciando a população, justifica que alguns pequenos lugares se convertam em aldeias; algumas aldeias em vilas; algumas vilas em cidades (LOPES, 2009, p. 23).

Observa-se que a busca por melhores condições de vida influenciam positivamente o comportamento da população, direcionando-as para aglomerações urbanas em busca de melhores rendas e empregos.

É neste cenário que, segundo Krasniqi (2009), ao analisarem os determinantes do empreendedorismo em mercados no sudeste europeu, demonstraram que a taxa de urbanização ${ }^{1}$ é um fator determinante na taxa de formação de novas empresas.

\footnotetext{
${ }^{1}$ Percentagem da população da área urbana em relação à população total.
} 
Evans e Jovanovic (1989) explicam que o aumento do desemprego pode estimular o crescimento do trabalho por conta própria, pois há uma redução do custo de oportunidade para se iniciar uma empresa, em função da falta de oferta de emprego no mercado competitivo. Por outro lado, regiões com elevada taxa de desemprego podem não estimular o empreendedorismo, nos casos em que a mão de obra local não possui habilidades, informação ou motivação para trabalhar por conta própria (AUDRETSCH et al, 2006; ROBSON, 1998).

Tais afirmações podem representar uma relação contraditória entre desemprego e trabalho por conta própria. Guerra e Grazziotin (2010) apontam o empreendedorismo como alternativa para que uma maior quantidade de indivíduos ingresse no mercado de trabalho, por meio da abertura de pequenas e médias empresas, que geram novos empregos.

Ainda, de acordo com Audretsch et al (2005) existem duas relações opostas entre desemprego e empreendedorismo. Alterações no desemprego geram variações positivas nas taxas de empreendedorismo, ou seja, o aumento na atividade empreendedora está relacionado à elevação do desemprego, ocasionando variações nas taxas de empreendedorismo, que representam impacto negativo nas subsequentes taxas de desemprego.

Para Barros e Miranda (2008), há dois tipos de empreendedorismo: por oportunidade e por necessidade. No empreendedorismo por oportunidade, o empreendedor aproveita-se efetivamente de uma situação conveniente para um novo negócio. Já no empreendedorismo por necessidade, o envolvimento no negócio acontece pela falta de oferta de trabalho ou renda.

Da mesma forma, aglomerações urbanas que oferecem estrutura de ensino, em especial, cursos técnicos e superiores de qualidade, tendem a estimular o empreendedorismo. Isto porque há uma relação entre instituições de ensino e empreendedorismo, uma vez que os estudantes possuem maiores chances de se tornarem empresários ou empregados de empresários (GLAESER; KERR, 2010).

De acordo com a Teoria do Empreendedorismo pelo Transbordamento do Conhecimento $^{2}$, Audretsch et al (2006) consideram que os novos conhecimentos e as novas ideias produzidas em grandes corporações ou centros de estudos, e que não são utilizadas pelo mercado ou pela instituição que as criou, geram oportunidades empreendedoras. Neste caso, o empreendedorismo passa a ser uma resposta endógena aos investimentos em conhecimento, que não foram incorporados anteriormente ao mercado.

Logo, pessoas com maior nível de escolaridade, mais bem instruídas, qualificadas e empreendedoras tendem a se estabelecer em aglomerações urbanas, por serem lugares com qualidade de vida e maior renda per capita. Consequentemente,

\footnotetext{
${ }^{2}$ Knowledge Spillover Theory of Entrepreneurship.
} 
fomentam o surgimento de novos negócios nessas regiões (GLAESER; KERR, 2010).

\section{Metodologia}

Realizou-se uma Análise Exploratória de Dados Espaciais (AEDE), com o intuito de revelar a padronização de clusters espaciais, regimes espaciais, nãoestacionaridade e outliers. A não-estacionaridade diz respeito à instabilidade espacial; enquanto os outliers, dizem respeito a observações atípicas. A AEDE, segundo Sabater, Tur e Azorin (2011, p. 261), é utilizada “...para verificar relações sistemáticas entre variáveis quando não existem expectativas claras sobre a natureza destas relações". Desta forma, a principal vantagem de sua utilização é analisar a dependência e a heterogeneidade espaciais (GONÇALVES, 2005).

Como medida de dependência, utilizou-se a estatística $I$ de Moran, que é a adequação de uma medida de correlação não espacial, aplicada em unidades espaciais, com características de disponibilidade de informações disponibilizadas em intervalos ou razões (SABA'TER et al, 2011). Sendo o I de Moran calculado da seguinte forma:

$$
I=\frac{n}{S_{0}} \frac{\sum_{i} \sum_{j} W_{i j} z_{i} z_{j}}{\sum_{i}^{n} z_{i}^{2}}
$$

Matricialmente (CLIFF E ORD, 1981):

$$
I_{t}=\left(\frac{n}{S_{0}}\right)\left(\frac{z_{t}^{\prime} W z_{t}}{z_{t}^{\prime} z_{t}}\right) t=1, \ldots, n
$$

Em que: $n$ "é o número de observações";

$S_{0}$ "é um escalar igual à soma de todos os elementos de $W$ ";

$z_{t}$ é o vetor de n observações para o ano t;

$W$ cé matriz de pesos espaciais e os subscritos $\mathrm{i}$ e $\mathfrak{j}$ se referem aos pares de localizações".

O valor esperado do $I$ de Moran é $-[1 /(n-1)]$, o qual é obtido caso haja distribuição aleatória dos dados. Assim, o I de Moran é equivalente ao grau de associação linear entre o vetor de " $q$ " (valores observados) ( $v$ e " $W \vec{z}$ " (média 
ponderada de valores vizinhos). Valores maiores (menores) que o esperado significa que a autocorrelação espacial positiva (negativa) (SABATER et al, 2011).

Ainda que possa indicar uma tendência geral de agrupamento dos dados, o $I$ de Moran não revela padrões locais de associação espacial por ser uma medida global, ou seja, a estrutura regional de autocorrelação espacial. Os instrumentos para verificar tal estrutura são o diagrama de dispersão de Moran; e os indicadores locais de associação espacial, denominados "LISA". Ambos são utilizados para desenvolver os testes de hipótese nula de distribuição aleatória, ao comparar os valores da localização específica com os valores de seus vizinhos.

O diagrama de dispersão de Moran representa os eixos "X" da variável padronizada; e no eixo dos "Y", o atraso espacial da variável padronizada. O LISA fornece informações sobre o grau de concentração de valores similares de uma determinada variável, em torno das unidades geográficas da amostra. Assim, o diagrama de dispersão classificará as relações espaciais locais entre as regiões e os seus vizinhos, com os seguintes resultados:

Padrão Alto-Alto (AA), no quadrante superior direito: regiões com alto valor da variável analisada, cercada de vizinhos com valores semelhantes;

Padrão Baixo-Baixo (BB), no quadrante inferior esquerdo: regiões com baixo valor da variável analisada, cercada de vizinhos com valores semelhantes;

Padrão Alto-Baixo (AB), no quadrante inferior direito: indica regiões de alto valor, com vizinhos com baixo valor;

Padrão Baixo-Alto (BA), no quadrante superior esquerdo: indica regiões de baixo valor, com vizinhos com alto valor.

Os padrões AA e BB significam associação espacial positiva, enquanto os padrões $\mathrm{BA}$ e $\mathrm{AB}$, associação espacial negativa.

\section{Modelo de regressão linear}

O modelo proposto é dado por:

\section{EMPREEN $=\beta_{1}+\beta_{2}$ TDES18 $+\beta_{3}$ RPC $+\beta_{4}$ OCCOM $+\beta_{5}$ OCPINDTR + $\beta 625$ SUPC $+\varepsilon$}

Onde:

EMPREEN: trata-se da variável dependente empreendedorismo, sendo explicada pelas seguintes variáveis independentes:

TDES18: mede o percentual de desocupados com mais de 18 anos de idade (taxa de desemprego). 
OCCOM: mede o percentual dos ocupados no setor comercial.

OCPINDTR: mede o percentual dos ocupados na indústria de transformação.

Tanto o OCCOM, quanto o OCPINDTR também são variáveis que podem mensurar a urbanização.

RPC: representa a renda domiciliar per capita das pessoas residentes nos municípios.

25SUPC: representa as pessoas com 25 anos ou mais com nível superior completo. Nesta metodologia adota-se esta variável para medir o grau de escolaridade nos municípios (educação).

$\boldsymbol{\varepsilon}$ : é o termo de erro do modelo.

\section{Descrição dos dados e instrumento de análise}

Foram utilizados arquivos no formato shape (shp) e a planilha eletrônica OfficeExcel, com base nas informações extraídas do Censo do ano de 2010, para todos os municípios do Estado do Rio Grande do Sul/RS. Os dados foram manipulados e as análises de econometria espacial foram realizadas com auxílio do software IpeaGEO.

\section{Resultados e Discussões}

A presente seção buscou apresentar os resultados encontrados, considerando as variáveis propostas no modelo utilizado na metodologia. Primeiramente, destacase a aplicação do Índice de Moran e, posteriormente, utiliza-se a aplicação de LISA e, por fim, a regressão linear.

\section{Índice de Moran}

Para medir a dependência espacial das variáveis analisadas por este trabalho, aplicado nos 496 municípios do estado do Rio Grande do Sul, foi utilizado o Índice de Moran Global, onde, observou-se autocorrelação espacial positiva. Os índices de OCINDTR e TDES18 apresentaram índices de, respectivamente, 0,6482 e 0,5167, com maior dependência espacial comparadas a variável 25SUPC, que obteve um índice menos significativo, com 0,09141, conforme demonstra Quadro 1. 


\section{Quadro 1 - Índice global de autocorrelação espacial para as variáveis}

\begin{tabular}{|l|l|r|}
\hline Variável Quantitativa & Índice & p-valor \\
\hline 25SUPC & 0,091413674 & 0 \\
\hline RPC & 0,410649535 & 0 \\
\hline EMPREEN & 0,139000832 & 0 \\
\hline OCCOM & & 0 \\
\hline OCINDTR & 0,648240718 & 0 \\
\hline TDES18 & 0,516707000 & 0 \\
\hline
\end{tabular}

Fonte: Resultados da pesquisa.

A Figura 1 apresenta o diagrama de espalhamento de Moran das variáveis deste estudo, no qual nota-se, para todas as variáveis, que boa parte dos municípios do Rio Grande do Sul estão localizados nos quadrantes com valores positivos, médias positivas, com padrão alto-alto e, nos quadrantes com valores negativos, médias negativas e padrão baixo-baixo. 
Figura 1: Diagrama de espalhamento de Moran.
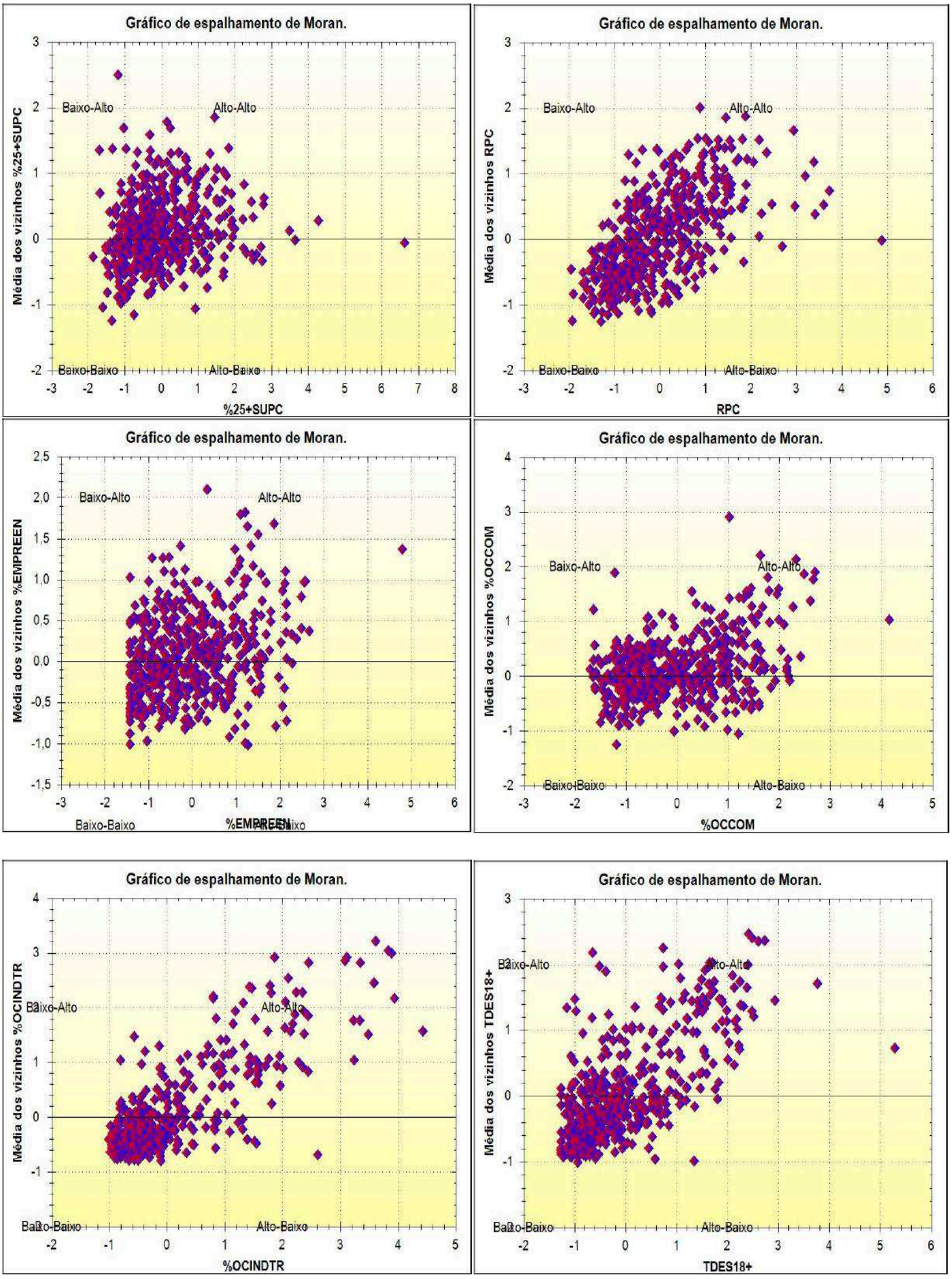

Fonte: Resultados da pesquisa. 
Para a variável 25SUPC, a qual apresenta o índice menos significativo, é possível observar na figura 1 que boa parte dos municípios estão localizados nos quadrantes com padrão alto-alto e baixo-baixo, o que comprova a dependência espacial desta variável, da mesma forma as variáveis RPC, EMPREEN e OCCOM apresentam maior concentração nos quadrantes 1 e 2. Com índices mais representativos, as variáveis OCINDTR e TDES18 apresentam elevada aglomeração nos quadrantes 1 e 2 .

\section{Metodologia LISA}

De acordo com Drucket al. (2004), para um grande número de distritos, como neste caso, onde foram analisados 496 municípios, é importante utilizar indicadores de associação espacial local que permitam identificar melhor os agrupamentos. Calculando-se o LISA foi possível classificar os municípios em função do nível de significância dos valores de seus índices locais. Na Figura 2 pode-se identificar regiões não significativas e com grau de confiança maior que 95\%. Assim, as áreas em destaque nos mapas são aquelas com características próprias, que merecem uma análise detalhada.

Figura 2: Indicador local de autocorrelação espacial (LISA).
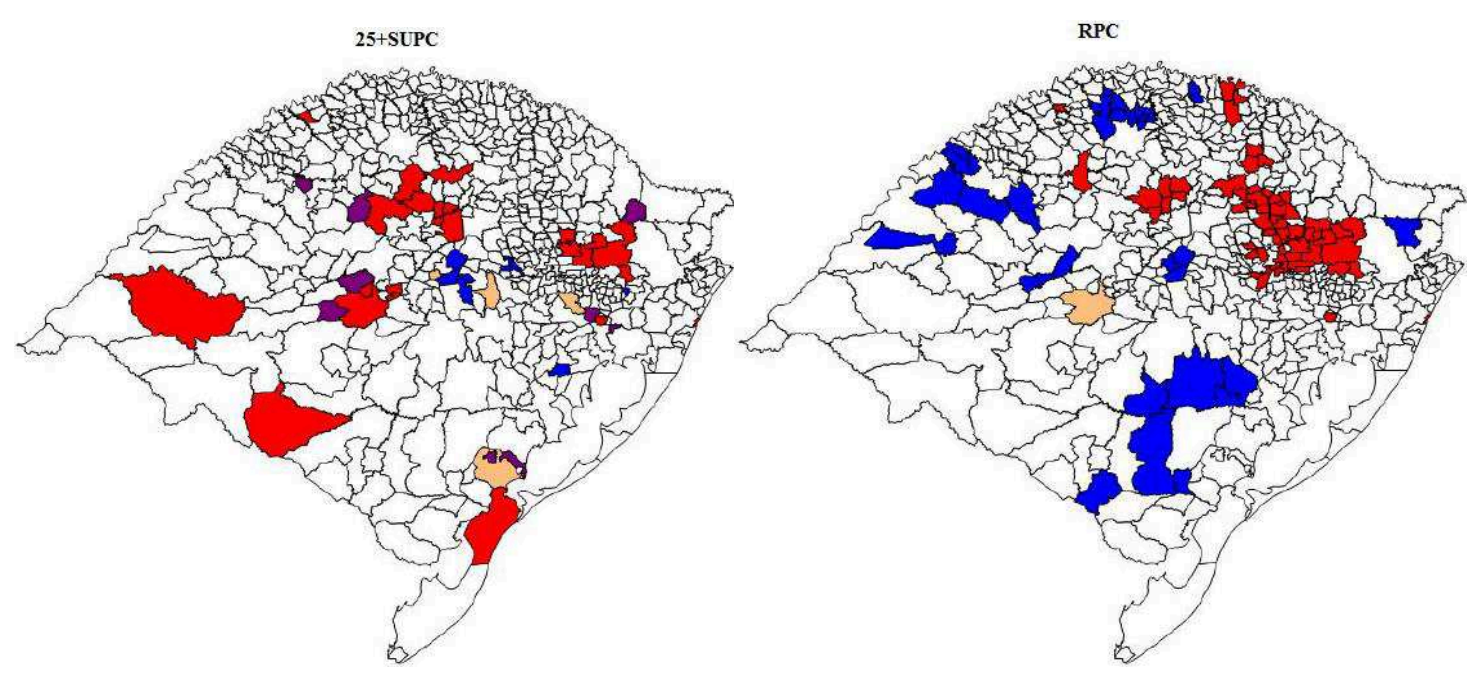

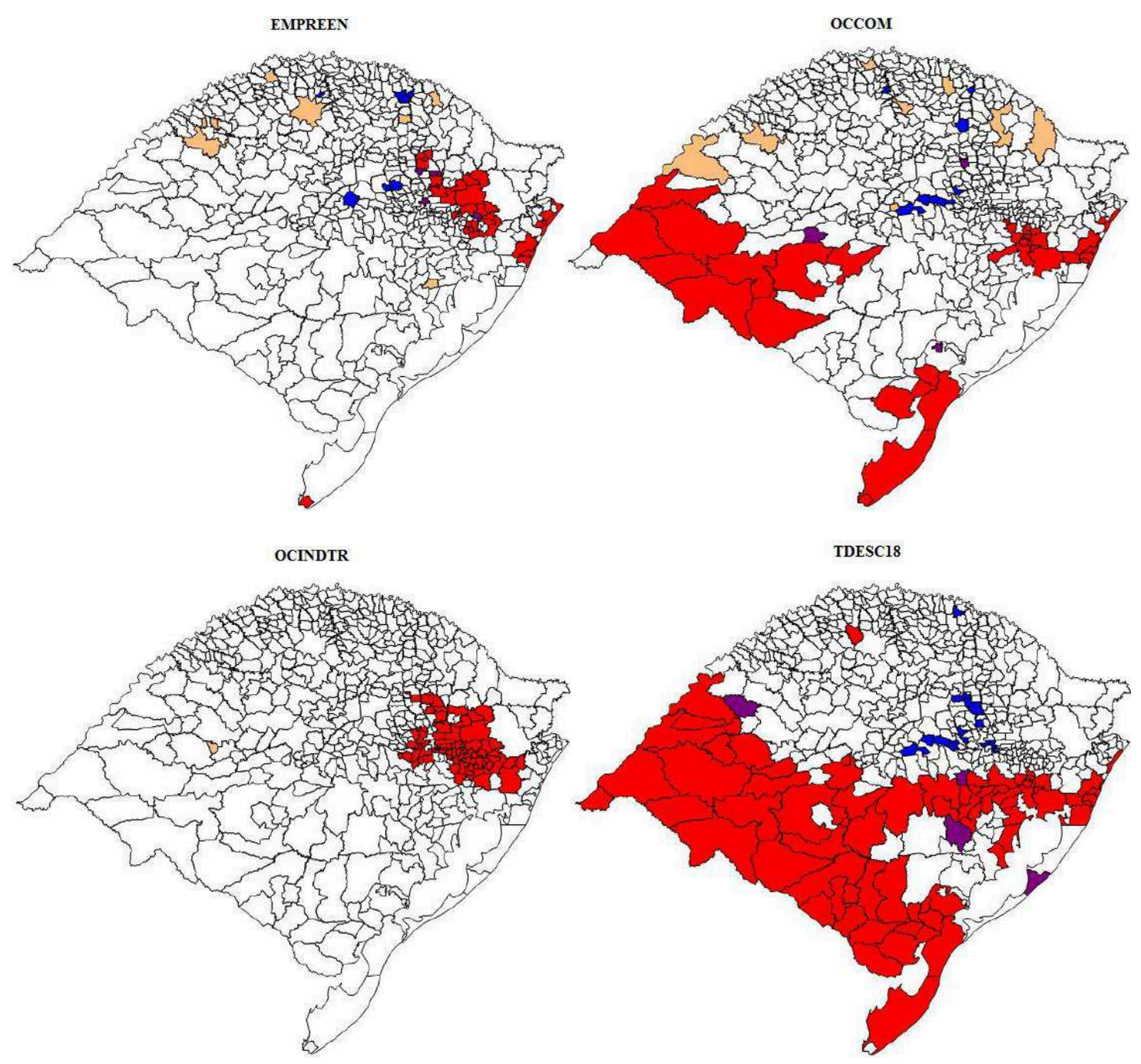

Fonte: Resultados da pesquisa.

Figura 3: Classificação de autocorrelação espacial (LISA)

\begin{tabular}{|l|l|}
\hline Classificação & Cores \\
\hline Não significativo & \\
\hline Alto-Alto & \\
\hline Alto-Baixo & \\
\hline Baixo-Baixo & \\
\hline Baixo-Alto & \\
\hline
\end{tabular}

Fonte: Resultado da pesquisa

Conforme a Figura 2, a maior concentração de municípios com perfil empreendedor (mapa EMPREEN) está nas regiões da serra gaúcha e litoral norte. 
No caso especifico das cidades localizadas na região da serra, constata-se uma população com alto nível educacional e elevada renda per capita, bem como concentração na atividade industrial, o que indica, segundo a literatura, que são locais com aglomeração de pessoas. Já as localidades com elevada taxa de desocupação estão estabelecidas na fronteira sul e parte da região centro-sul, não relacionando o empreendedorismo ao desemprego.

Observa-se que o nível de escolaridade não apresenta aglomeração espacial, pois, de acordo com o mapa (25SUPC), Figura 2, existe uma distribuição em várias regiões do estado do Rio Grande do Sul. Já as variáveis renda e industrialização estão concentradas na serra gaúcha (região centro-nordeste), o comércio apresenta forte aglomeração espacial na fronteira-oeste, região sul e região leste. As regiões com maior taxa de desemprego encontram-se na fronteira-oeste, fronteira-sudeste, região sul e pedaço das regiões centro-leste e centro-sul.

Observa-se na figura 2 que regiões com perfil empreendedor são urbanizadas e possuem elevada renda per capita, portanto, a aplicação da econometria espacial, neste estudo, confirma as teorias apresentadas na seção 2 , nas quais consideram que nível de urbanização, renda e educação são aspectos que influenciam no empreendedorismo.

\section{Regressão Linear}

Considerando a variável explicada e as variáveis explicativas propostas neste trabalho, o modelo de regressão linear foi definido como: EMPREEN = 0,465407 - 0,063036 TDES18 + 0,000519 RPC + 0,132392 OCCOM + 0,023338 OCINDTR + 0,081766 25SUPC. O coeficiente de determinação $\left(\mathrm{R}^{2}\right)$ e o coeficiente de determinação ajustado ( $\mathrm{R}^{2}$-ajustado) indicam que aproximadamente $51 \%$ da variação da variável EMPREEN pode ser explicada pelo modelo proposto. Todas essas medidas são sustentadas pela suposição de dados normais multivariados.

A análise dos resíduos mostrou que eles apresentam distribuição Normal com 95\% de nível de confiança (teste de Anderson Darling = 2,373902). Por meio do teste Breusch-Pagan foi possível verificar que o $p$-valor foi superior ao nível de significância considerado, 5\%. Desta forma, não rejeita-se a hipótese nula e detecta-se a homocedasticidade. 
Quadro 2 - Estimação via OLS (Mínimos Quadrados Ordinários)

\begin{tabular}{|l|r|r|r|r|}
\hline Variável & \multicolumn{1}{|l|}{ Coeficiente } & Erro padrão & Estatística t & \multicolumn{1}{l|}{ P-valor } \\
\hline Intercepto & $-0,465407$ & 0,139179 & $-3,343943$ & 0,000826 \\
\hline TDES18 & $-0,063036$ & 0,025057 & $-2,515749$ & 0,011878 \\
\hline RPC & 0,000519 & 0,000233 & 2,228482 & 0,025848 \\
\hline OCCOM & 0,132392 & 0,014991 & 8,831726 & 0,000000 \\
\hline OCINDTR & 0,023338 & 0,004182 & 5,580907 & 0,000000 \\
\hline 25SUPC & 0,081766 & 0,021258 & 3,846382 & 0,00012 \\
\hline$R^{2}$ (coeficiente de determinação): & & & 0,516723 \\
\hline$R^{2}$-ajustado: & & & 0,511792 \\
\hline
\end{tabular}

Fonte: Resultados da pesquisa.

Quadro 3 - Teste para Homocedasticidade dos Resíduos (com termos quadráticos e produtos cruzados)

\begin{tabular}{|l|r|}
\hline Estatística do teste de Breusch-Pagan (teste qui-quadrado): & 60,805584 \\
\hline P-valor do teste de Breusch-Pagan (teste qui-quadrado): & 0,000002 \\
\hline
\end{tabular}

Fonte: Resultados da pesquisa.

\section{Quadro 4 - Testes de Normalidade dos Resíduos}

\begin{tabular}{|l|r|}
\hline Estatística de Anderson-Darling: & 2,373902 \\
\hline Estatística de Kolmogorov-Smirnov: & 0,068525 \\
\hline
\end{tabular}

Fonte: Resultados da pesquisa.

No modelo da regressão linear exposto acima, detecta-se a homocedasticidade e a normalidade dos dados, o que indica a possibilidade de aplicação de econometria espacial para os dados selecionados. Nesta seção não foram considerados os aspectos relacionados à dependência espacial, servindo como informação preliminar para execução da AEDE.

\section{Considerações Finais}

Ao realizar a análise espacial das variáveis estudadas neste trabalho, observou-se que, no Rio Grande do Sul, regiões onde a população apresenta maior nível educacional e renda per capita, bem como, com baixa taxa de desocupação, são propensas a serem mais empreendedoras que outras, destacando-se a serra gaúcha e litoral norte nestes quesitos. Ainda, com base nas informações apuradas, 
comparando as diferentes regiões, conforme a distribuição espacial apresentada na pesquisa posposta, indicando que o estado apresenta características para o empreendedorismo por oportunidade e não por necessidade.

Localidades com alto índice de desempregados são menos empreendedoras, sendo a fronteira sul e parte do centro gaúcho as regiões onde estão localizados os municípios com maior concentração de população desocupada. Nesta pesquisa, tais regiões apresentaram resultados não significativos para variável empreendedorismo.

Por fim, observou-se que o empreendedorismo apresentou correlação com as variáveis explicativas e se distribui para as regiões vizinhas. Portanto, de forma geral, os métodos aplicados neste estudo comprovaram-se eficientes para a identificação da autocorrelação espacial.

Diante da aplicação da AEDE, nas variáveis em estudo, pode-se afirmar que para esta pesquisa confirmam-se algumas vertentes teóricas que relacionam empreendedorismo e desenvolvimento regional, associando regiões urbanizadas, com maior renda per capita e nível educacional com maior potencial empreendedor.

As conclusões apresentadas neste trabalho estão limitadas as variáveis incluídas nesta pesquisa, portanto sugerem-se que pesquisas futuras sobre o tema acrescentem outras variáveis socioeconômicas e culturais, bem como a interferência dos agentes governamentais como participantes do processo de empreender.

\section{Referências}

AUDRETSCH, D. B.; CARREE, M. A.; STEL, A. J.; THURIK, R. Does selfemployment reduce unemployment? Scales-paper N200504, Zoetermeer: EIM Business \& Policy Research, 2005.

AUDRETSCH, D. B.; KEILBACH, M. C.; LEHMANN, E. E. Entrepreneurship and economic growth. New York, OxfordUniversity Press, 2006.

BARROS, A. A de; MIRANDA, C. M.; Empreendedorismo e Crescimento Econômico: uma Análise Empírica. Revista de Administração Contemporânea - RAC, Curitiba, v. 12, n. 4, p. 975-993, out./dez. 2008.

BARROS, A. A.; PEREIRA C. M. A. Empreendedorismo e Crescimento Econômico: uma Análise Empírica. RAC, Curitiba, v. 12, n. 4, p. 975-993, Out./Dez. 2008. 
BLANCHFLOWER, D. G.; MEYER, B.A longitudinal analysis of young entrepreneurs in Australia and the United States. Small Business Economics,v. 6, p. 1-20, 1994.

CLIFF, A. D. and ORD, J.K. Spatial processes: models and applications. Pion, London, 1981.

DRUCK, S.; CARVAlHO, M. S.; CÂMARA, G.; MONTEIRO, A. V. M. Análise espacial de dados geográficos. Brasília: EMBRAPA, 2004.

EVANS, D. S.; JOVANOVIC, B. Estimates of a model of entrepreneurship choice under liquidity constraints. Journal of Political Economy, v. 97, p. 657674. 1989.

FIGUEIREDO, A. M. As políticas e o planeamento do desenvolvimento regional. In: COSTA, José da Silva; NIJKAMP, Peter (Org.). Compêndio de Economia Regional: Teoria, Temáticas e Políticas. v. 1. Coimbra: Principia, 2009.

FRANÇA, K.; FURTADO, B. A. Experiências de Governança Metropolitana Internacional: Os casos dos Estados Unidos e Canadá. Texto para Discussão $n^{\circ}$ 1855. Instituto de Pesquisas Econômicas Aplicadas (IPEA): 2013.

GLAESER, E. L.; KERR, W. R. What makes a city emptrepreneurial? Harvard Kennedy School, 2010.

GONÇALVES, E. A. Distribuição Espacial da Atividade Inovadora Brasileira: Uma Análise Exploratória. Texto para Discussão n ${ }^{\circ} 246$. Centro de Desenvolvimento e Planejamento Regional da Universidade Federal de Minas Gerais (CEDEPLAR/UFMG), 2005.

GUERRA, M. J.; GRAZZIOTIN, Z. J. Educação empreendedora nas universidades brasileiras. In: LOPES, R.M. A. (Orga.). Educação empreendedora: conceitos, modelos e práticas. Cap. 4. Rio de Janeiro: Elsevier; São Paulo: Sebrae, 2010.

KNIGHT, F. H. (1921). Risk, uncertainty and profit. New York: Houghton Mifflin. Evans e Jovanovic, 1989.

KRASNIQI, B. A. Personal, household and business environmental determinants of entrepreneurship, Journal of Small Business and Enterprise Development, v. 16 Issue: 1, p.146-166. 2009. 
LONGENECKER, J. G.; MOORE, C. W. PET'TY, J. W. Administração de pequenas empresas: ênfase na gerência empresarial. São Paulo: Makron Books, 1997.

LOPES, A. S. O Espaço Econômico. IN: COSTA, J. S.; NIJKAMP, P. (Org.). Compêndio de Economia Regional: Teoria, Temáticas e Políticas. v. 1. Coimbra: Principia, 2009.

LUMPKIN, G. T.; DESS, G. G. Clarifying the entrepreneurial orientation construct and linking it to performance. Academy of Management Review, v. 21, n. 1, p. 135-72, 1996.

MENEZES, G.; CANEVER, M. D. A estrutura empresarial e a taxa de formação de empresas: Análise de sua dinâmica. Revista Brasileira de Economia de Empresas. 2016; 16(1): 111-123

NIJKAMP, P. Empreendedorismo num contexto espacial: retrospectiva e perspectiva. IN: COSTA, José da Silva; NIJKAMP, Peter (Org.). Compêndio de Economia Regional: Teoria, Temáticas e Políticas. v. 1. Coimbra: Principia, 2009.

PAIVA, M. S.; CUNHA G. H. M.; SOUZA JR C. V. N.; CONSTANTINO M. Inovação e os efeitos sobre a dinâmica de mercado: uma síntese teórica de Smith e Schumpeter. Interações, Campo Grande, MS, v. 19, n. 1, p. 155-170, jan./mar. 2018.

PETERS, T. Não é hora para conservadorismo. Folha de São Paulo, São Paulo, 1 set. 2002.

ROBSON, M. T. Self-employment in the UK regions. Applied Economics, v. 30, p. $313-323,1998$.

SABATER et al. Análise Exploratória de Dados (AEDE). IN: COSTA, José da Silva; DENTINHO, Tomaz Ponce (Org.). Compêndio de Economia Regional: Métodos e Técnicas de Análise Regional. v. 2. Cascais: Principia, 2011.

SCHUMPETER, J. A. Capitalismo, socialismo e democracia. Rio de Janeiro: Zahar, 1984.

SCHUMPETER, J. The theory of Economic Development. Cambridge: Harvard University Press, 1934. 
THORNTON, P. H.; RIBEIRO-SORIANO, D.; URBANO, D. Socio-cultural factors and entrepreneurial activity: An overview. International Small Business Journal, v. 29, n. 2, p. 105-18, 2011. 
Endereço para correspondência:

Ricardo Höher - ricardo.hoher@ufsm.br Av. Roraima, 1000 - Prédio 70 - Camobi 97105900 - Santa Maria/RS, Brasil Telefone: (55) 32209420

Mário Jaime Gomes de Lima - mariojgl@gmail.com Av. Victor Barreto, 2288 - Centro 92010000 - Canoas/RS, Brasil Telefone: (51) 34768500

Adelar Fochezatto-adelar@pucrs.br Av. Ipiranga, 6681 - Prédio 50 - PARTENON 90619900 - Porto Alegre/RS, Brasil Telefone: (51) 33203500 Ramal: 3547 